\title{
Tricuspid Valve Ring Annuloplasty in a Patient with 36-year in-situ Functioning Bjork-Shiley Valve in Mitral Position
}

\author{
(1) Atike Tekeli Kunt, (1) Kanat Özışık, (1) Orhan Eren Günertem, (1) Ali Baran Budak, \\ (1) Naim Boran Tümer, (1) Seyhan Babaroğlu, (1) Serdar Günaydın
}

Health Sciences University Ankara Numune Training and Research Hospital, Clinic of Cardiovascular Surgery, Ankara, Turkey

\begin{abstract}
The Bjork-Shiley valve (BSV) was one of the first tilting disc valve prostheses that were used. We report a patient with a still functioning BS mitral valve prosthesis implanted

and required a redo surgery for tricuspid valve regurgitation.

Keywords: Bjork-Shiley valve, tricuspid regurgitation, ring annuloplasty
\end{abstract}

\section{Introduction}

The Bjork-Shiley (BS) mechanical valve (ShileyCorp, Irvine, CA) was the first tilting disc valve used for the management of valvular heart disease ${ }^{(1)}$. It was one of the most implanted mechanical valves between 1970s and 1980s; however, the valve's production was stopped due to increased rate of fracture and disc escape that resulted in high patient mortality. We report a patient with a
BS mitral valve prosthesis implanted in 1981 and still functioning.

\section{Case Report}

A 56-year-old female patient with the symptoms of leg swelling and dyspnea resulted from right ventricular failure was admitted to our clinic. She had undergone a mitral valve replacement with a BS tilting disc valve 36 years ago (Figure 1). Her echocardiogram revealed

\footnotetext{
Address for Correspondence: Atike Tekeli Kunt, Health Sciences University Ankara Numune Training and Research Hospital, Clinic of Cardiovascular Surgery, Ankara, Turkey

Phone: +90 5327467869 e-mail: atikemd@gmail.com ORCID: orcid.org/0000-0001-9764-7393

Received: 07.05.2019 Accepted: 15.08.2019

Cite this article as: Tekeli Kunt A, Özışık K, Günertem OE, Budak AB, Tümer NB, Babaroğlu S, Günaydın S. Tricuspid Valve Ring Annuloplasty in a Patient with 36-year in-situ Functioning Bjork-Shiley Valve in Mitral Position. EJCM 2019;7(3):153-155.

DOI: 10.32596/ejcm.galenos.2019.05.026
}

Presented in: This study was presented in 14th International Congress of Update in Cardiology and Cardiovascular Surgery, April 5-8, 2018. Antalya, Turkey.

${ }^{\circ}$ Copyright 2019 by Heart and Health Foundation of Turkey (TÜSAV) / E Journal of Cardiovascular Medicine published by Galenos Publishing House. 

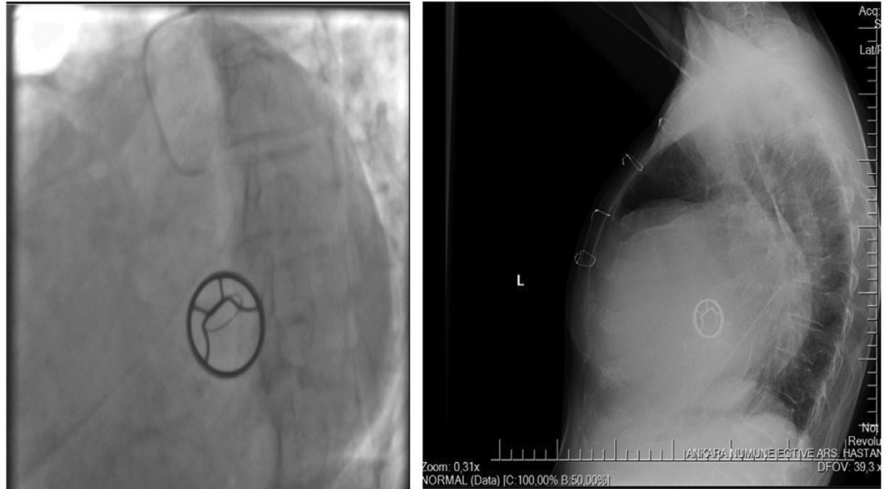

Figure 1. A. Preoperative coronary angiogram view showing Bjork-Shiley tilting disk valve in mitral position, B. Preoperative lateral chest X-ray view showing Bjork-Shiley tilting disk valve in mitral position

a well-seated, normally functioning prosthetic mitral valve with a mean pressure gradient of $5 \mathrm{mmHg}$. The left atrium was enlarged $(8 \mathrm{~cm})$ and the left ventricle remained normal in size. Left ventricular systolic function was normal with an estimated ejection fraction of $65 \%$. The size of the right atrium was $12 \times 10 \mathrm{~cm}$, the diameter of the inferior vena cava was $4.1 \mathrm{~cm}$. She had a severe tricuspid valve (TV) regurgitation and moderate pulmonary hypertension (systolic pulmonary artery pressure $=50 \mathrm{mmHg}$ ). Tricuspid regurgitant velocity (TRV) was $3.3 \mathrm{~m} / \mathrm{s}$ and tricuspid annular plane systolic excursion (TAPSE) was $13 \mathrm{~mm}$. We planned to perform only $\mathrm{TV}$ repair and not to touch the functioning $\mathrm{BS}$ valve.

After obtaining informed consent from the patient for both the surgery and the use of her medical records, resternotomy was carried out using cardiopulmonary bypass under the right femoral artery and vein cannulation. We decided to perform TV repair without an aortic crossclamp, so we did not arrest the heart. We explored the TV through the right atriotomy while the heart was beating and implanted a 3D tricuspid annuloplasty ring ( $\mathrm{Size}=32$ mm, CONTOUR 3D ${ }^{\circledR}$, Medtronic, USA).

Postoperative recovery was uneventful. The postoperative control echocardiography showed normal functioning BS valve in mitral position and no TV regurgitation was observed. She was discharged on the $5^{\text {th }}$ postoperative day and she is doing well for 18 months after the procedure.

\section{Discussion}

The BS valve was the first tilting disc mechanical valve implanted for heart valve replacement ${ }^{(1)}$. It was a lowprofile mechanical valve with a Delrin disc. As this initial Delrin disc resulted in many structural complications such as wear or fracture, it was replaced by a pyrolytic carbon $^{(2,3)}$. However, these structural changes of the BS valve could not prevent the valve from strut fractures and in the end, BSV was recalled from the market. In the literature, there are many case series and reports that show structural deformities of the $\mathrm{BSV}^{(4-6)}$. There are also case reports about BSV, which suggest that these valves are still functioning for 25- 42 years $^{(7,8)}$.

Prophylactic replacement of these valves which were prone to fracture was a concern especially in the early years of implantation of BSV and this peak of replacement was mainly due to infective endocarditis ${ }^{(9)}$. The other peaks of replacement were mainly after the identification and publication of risk factors for outlet strut fracture in $1992^{(10)}$. However, there have been debates on the necessity of these replacements. Guidelines for BS valve replacement were introduced to prevent unnecessary reoperations and these had a positive effect on treatment $\operatorname{decisions}^{(10)}$.

\section{Conclusion}

The implanted valve in our patient has been functioning well for 36 years. The patient underwent a TV repair for TV regurgitation. BSV that was implanted in our patient had no structural abnormalities and it was functioning with a low-pressure gradient $(5 \mathrm{mmHg}$ ). We decided to keep this normal functioning and non-destructed valve in place and not to perform a left atriotomy. We performed ring annuloplasty through right atriotomy and the postoperative course was uneventful. Since we did not touch the working BSV, we could perform beating heart TV repair and we think that these precautions resulted in an uncomplex operation and uneventful perioperative period. 


\section{Ethics}

Informed Consent: Informed consent was obtained from the patient.

\section{Authorship Contributions}

Surgical and Medical Practices: A.T.K., K.Ö., S.G., O.E.G., Concept: A.T.K., N.B.T., A.B.B., Design: A.T.K., N.B.T, A.B.B., Data Collection or Processing: A.T.K., K.Ö., S.G., O.E.G., S.G., Analysis or Interpretation: A.T.K., N.B.T., O.E.G., Literature Search: A.T.K., Writing: A.T.K.

Conflict of Interest: No conflict of interest was declared by the authors.

Financial Disclosure: The authors declared that this study received no financial support.

\section{References}

1. Björk VO. A new tilting disc valve prosthesis. Scand J Thorac Cardiovasc Surg 1969;3:1-10.
2. Björk VO. Disc wear in the Björk-Shiley tilting disc valve. Experiment and clinical observation. Scand J Thorac Cardiovasc Surg 1971;5:87-91.

3. Björk VO. The pyrolytic carbon occluder for the Björk-Shiley disc valve prosthesis. Scand J Thorac Cardiovasc Surg 1972;6:109-13.

4. Cane ME, McGrath LB. Elective reoperation for a strut fracture in a BjörkShiley convexo-concave mitral valve. Ann Thorac Surg 1994;58:1184-5.

5. Scalia D, GiacominA, Da Col U, et al. Successful treatment of a patient after sudden loss of the disc in a Björk-Shiley convexo-concave mitral prosthesis. Thorac Cardiovasc Surg 1987;35:318-20.

6. Uchino G, Yoshida H, Sakoda N, et al. Outlet strut fracture and leaflet escape of Bjork-Shiley convexo-concave valve. Gen Thorac Cardiovasc Surg 2017;65:358-60.

7. Gunn JM, Malmberg M, Vähäsilta $T$, et al. Thirty-year results after implantation of the Björk-Shiley Convexo-Concave Heart valve prosthesis. Ann Thorac Surg 2014;97:552-6.

8. Shaikh A, Jamil Tajik A. Excellence and Durability: A Normally Functioning Björk-Shiley Flat-Disc Prosthesis 42 Years Post Implantation. J Heart Valve Dis 2016;25:237-9.

9. Mansur AJ, Dal Bó CM, Fukushima JT, et al. Relapses, recurrences, valve replacements, and mortality during the long-term follow-up after infective endocarditis. AmHeart J 2001;141:78-86.

10. van Gorp MJ, Steyerberg EW, van der Graaf Y. Decision guidelines for prophylactic replacement of Björk-Shiley convexo-concave heartvalves: impact on clinical practice. Circulation 2004;109:2092-6. 